\title{
The Policy Research for the Improvement of Excessive Marriage Expense in South Korea
}

\author{
Donghun Yoon ${ }^{1}$ \\ ${ }^{1}$ Seoul Center, Korea Basic Science Institute, South Korea \\ Correspondence: Donghun Yoon, Seoul Center, Korea Basic Science Institute, 145 Anam-ro, Seongbuk-gu, \\ Seoul, 02841, South Korea.
}

Received: December 14, 2017

Accepted: December 29, 2017 Online Published: January 8, 2018

doi:10.5539/ibr.v11n2p44

URL: https://doi.org/10.5539/ibr.v11n2p44

\begin{abstract}
Excessive marriage-related expenses have become a serious social problem in South Korea. This has led to marriage delay, a low birthrate, the acceleration of an aging society, decreased national economic growth, and employment problems, among others. In South Korea, the young unmarried men and women cannot adequately prepare to shoulder the excessive expenses related to getting married in the future, as well as the high cost of purchasing a house. In fact, almost all of them are being supported by their parents in their marriage preparations or have secured a loan for such purposes. Small weddings and desirable consumption are thus aggressively being promoted for the prevention of excessive marriage-related expenses in South Korea. The reality, howe ver, is very different. In this study, 1,000 persons (500 men, 500 women) in Seoul, South Korea with less than 5 years of marriage were surveyed for the analysis of excessive marriage-related expenses. The analysis results show that marriage expense support has long-term reciprocity and is statistically significant. The economic support beneficiary model is statistically significant both among the men and the women for childcare, housework, and economic support provision. The economic support provision model, on the other hand, is statistically significant among both the men and the women in terms of housework support.

This paper discusses and presents the policy direction for addressing the problem of excessive marriage-related expenses in South Korea. It is believed that the policy direction proposed by this study will also have global implications and will become useful for addressing the problem of excessive marriage-related expenses through research result sharing.
\end{abstract}

Keywords: policy research, marriage, marriage expenses, excessive expenses, men, women, economic support, family, young people

\section{Introduction}

Marriage is decided through mutual agreement between a man and a woman (Mair, 2006). In recent years, the same sex marriage is legally recognized in many Western countries (United States, Canada, United Kingdom, France, Germany, Netherlands, Belgium, etc.). It should also gain social recognition, which is realized through the wedding, a form of social announcement of a couple's marriage in front of the couple's family members, relatives, friends, colleagues, acquaintances, etc (Lin, et al., 2017; Wong, 2003). The wedding is the most common social phenomenon, but as a social convention, it entails economic costs (Allendorf \& Ghimire, 2013; Carrington, 2002; Quinn, 2007). In South Korea, many families spend excessively for the wedding ceremony, through negotiations between the couple's families. Excessive marriage-related expenses are a general phenomenon related to marriage preparations in the country. As a consequence, the number of young unmarried men and women has rapidly increased of late due to the young men and women's delaying and dodging of marriage. The increase in the first-marriage age is a representative index for this. Job, marriage, and childbirth abandonment have also become social buzzwords and serious social problems in South Korea, and excessive marriage-related expenses is the major cause of marriage abandonment. In the statistical report (2016) of Korea National Statistical Office (KOSTAT), the average age of the men in South Korea at the time of their first marriage is 32.8 , and that of the women is 30.1. The major reason for the delaying and dodging of marriage is the excessive financial burden imposed by marrying. According to the research report (2016) of the Ministry of Gender Equality \& Family (MOGEF) of South Korea, the average cost of marriage for the South Korean men is USD152,685, and that for the South Korean women is USD82,212. The high cost of purchasing a house 
accounts for a large portion of the excessive marriage-related expenses, and the house lease cost is almost equal to the house purchase cost. Young unmarried men and women cannot adequately prepare themselves to shoulder the house purchase cost because the country's financial system lacks provisions for mortgage, house lease cost support, and house purchase cost support. The parents are thus the ones who often shoulder a considerable part of the excessive marriage-related expenses, which imposes a financial burden on them. Marriage means that a man and a woman form a new family and maintain their independence in terms of economic resource management, but at present, the parents shoulder a large part of their children's marriage-related expenses so that their children can have an independent economic life, and based on this, their children acquire the ability to lead their own families independently. In South Korea, however, the parental support of the children does not end with the children's marriage. If a child requests for economic support from his/her parents after marriage, the parents usually oblige, providing their married children support for their purchase of a house and a car, and providing their married children childcare support, etc. This has become a serious social problem in South Korea. This article presents and discusses the proposed policy direction for addressing the problem of excessive marriage-related expenses. It is expected that the policy direction presented in this paper for addressing the problem of excessive marriage-related expenses will contribute to the prevention thereof, and of marriage delay. It is also believed that the policy direction proposed by this study will have global implications and will become useful for addressing the problem of excessive marriage-related expenses through research result sharing.

\section{Theoretical Review}

\subsection{Transactional Characteristics of Marriage}

Family relations include blood relationships and relationships with one's in-laws. The parent-child relationship is a representative blood relationship while conjugal relations are representative in-law relationships (Amato, 2007). Many anthropologists believe that the history of marriage can be traced to the legal position of women in the past, and their legal and economic dependence on men, who were the ones who possessed assets (Sherman \& Badillo, 2007). Actually, marriage in the olden times was a contractual relationship that included various rights and obligations based on economic transactions rather than on romantic love. Scholars' definition of marriage confirms that marriage involves the transfer or flow of rights. It is a customary transaction that establishes the justification for a child to be born in the future from the relations between a man and a woman, a kind of transaction, and the resulting contract (Brake, 2007). The bride price and dowry are representative transactional characteristics of marriage. The bride price is the reward for childbirth and the accompanying labor, with the newborn transferred to the groom. It is a value that the family of the groom pays to the family of the bride, and is based on the importance accorded to the labor force of women as well as to the low status of the women in the society (Fincham, et al., 2007). The dowry consists of goods or money given by the groom's family to the bride's family. It is given to the bride and is regarded as her share in the assets of her family. In most cases, the transactions are done, and a deal is reached, by the parents and relatives of the bride and groom. The rationale behind this is that the groom and bride cannot shoulder their marriage-related expenses by themselves alone as these are excessive. The marriage is decided in accordance with the opinion of the one who will shoulder the marriage expenses, with the bride and groom agreeing formally to the decision (Mincy, et al., 2009). Since recently, however, women's property rights have been guaranteed, and the decision to marry has become voluntary on the part of the men and women in modern society. In most cases, the practices of spending much to prepare for the newly married couple's new life (house purchase, etc.) and of the ceremonial spending (wedding, honeymoon, etc.) are difficult to explain because in South Korea, the newly married couples are independent.

\subsection{Social Exchange Theory}

The social exchange theory combines the economics, psychology, and sociology of mankind. It provides the framework of human relationships and gains sympathy from people for such relationships (Gottman, et al., 2002). This theory states that social interactions are formed and sustained for the motive of promoting people's respective interests, and that all the social-interaction actors progress while participating in a reciprocal compensatory behavioral system. The understanding of exchange resource and exchange method is premised on the analysis of the exchange situation (Singh, 2012). The exchange situation can be classified into the distributive exchange situation or the productive exchange situation. In a distributive exchange situation, the resource exchanged by the parties involved is a single type of the same-value resource. The exchange method involves direct transaction for the counterpart resource, and the characteristics of the relationship are determined through the relative exchange ratio of resources (Lefgren, \& McIntyre, 2006). In a productive exchange situation on the other hand, the resources exchanged are the independent resources of each of the actors. The exchange method involves the joint consumption of the items jointly produced as calculated in combination with the other party's resources after the joint venture, or exchanging them with the other resources of an outsider (Groot \& 
Van Den Brink, 2003). To justify the hypothesis that the marriage cost will prove to be a productive exchange, the characteristics of the exchange are presented as follows. The first phase in the marriage process, in which a marriage decision is made from among the several promising prospects. According to the social exchange theory, when a person perceives himself/herself to be in a state of equilibrium, an exchange relationship is established, which means that the two persons have equilibrated in terms of the marriage exchange resources. Equilibrium here is in terms of complementarity. The second phase is the marriage preparation, which is the physical basis of life after the marriage decision. The bride and groom start a cooperative relationship in an exploratory relationship after making a marriage decision, and contribute their own independent resources to come up with a worthy product. In this case, the resources to be jointly invested are the marriage-related expenses. It has the transaction character of a productive exchange. One factor that is considered in determining the value of the product in a productive exchange is the quality of the invested resource unit. The more valuable the invested resource unit is, the greater the efforts that will be exerted to invest the best resource so that a greater value can be created. The third phase is the beginning of the marriage relationship with the end of the honeymoon. At this phase, the jointly invested products consumed through the interactive combination of the jointly invested resources are consumed. It is also assumed that this phase is related to marriage satisfaction. A productive exchange resource is an explanatory framework that applies to general marriage situations (McKenzie \& Dales, 2017; Meltzer, et al., 2013). It is necessary to analyze the multilateral approach to the marriage situation, in which the contract between the couple's resources necessary for their marriage is entered into before the formal cooperative relationship begins.

\subsection{Consumption Culture of Marriage}

The composition of cultural text is very different from the quantitative concept of marriage in the approach to determining the qualitative aspect of marriage. It is a natural process of growth due to the characteristics of marriage, and is strongly attributed to a ritual reflecting values, cultures, and norms. The visible value of two families, which is higher than the original value of the combination of two persons, creates a new consumer culture of marriage (Legros \& Newman, 2010; Madison \& Madison, 2013). In South Korea, the group culture is more important than the individual culture. Other people's eyes are perceived to be the most fearful factor. Therefore, ostentation rather than individual substance has a direct impact on the outcome of consumption. Critical opinions about the marriage of other persons are expressed, but there are contradictory consequences on one's own marriage. The wedding ceremony in South Korea has not improved from days past, and has been criticized. In the South Korean society, marriage is a typical consumption-related decision-making process in which the competitiveness and social status of a family are presented to the world. The marriage cost has a higher correlation with the income level or social status of the couple's parents than with the income of the man and woman to be married. The parents' influence on the marriage cost has a great impact. Marriage needs preparation in terms of the wedding ritual, honeymoon, etc., and focus should be placed on the cost, time, and efforts to be expended. Although weddings are of great value, excessive marriage-related expenses has become a serious problem. Thus, since recently, the young persons in South Korea have come to prefer a substantial but low-cost marriage. The consumers are bound to form a creative and sustainable consumer culture for such new creative practice through the consumption of small weddings.

\section{Global Marriage Culture Trend}

In the United States, weddings are traditionally gorgeous. Of course, this means that the weddings are maximized according to the life and economic situation of the couple to be married. The marriage cost almost entirely involves the expenses for the wedding ceremony itself and the reception. The focus is on having wonderful weddings and great parties, even if holding these will entail excessive expenses. Since recently, however, many men and women in the United States have opted to marry frugally. Marriage-related expenses rarely become huge, except those for the wedding ceremony itself. The marriage culture is becoming increasingly practical. Parties and events are also more frugal than spectacular.

The United Kingdom also has a pragmatic and frugal marriage culture. As $90 \%$ of the British are Anglican, most of the weddings are held in the church. The groom takes care of the expenses, such as renting a wedding venue, and the bride pays for the bouquets, corsages, decorations, etc. Since recently, the grooms and brides have been very practical with regard to their marriage cost. Couples jointly shoulder the marriage expenses as well as the purchase cost of their new house. Also, the number of couples who put their property under both their names is increasing.

In Japan, most of the young people start their new life by borrowing money to purchase a small house. The wedding ceremony is gorgeous, and most of the young people prepare themselves for their marriage by saving. 
They themselves shoulder the cost of their own marriage, and they celebrate and consider it the most splendid day in their life. They believe that they cannot impose on their parents that the latter provide them with marriage expense support. This is a common belief among the young people in Japan. The number of single people is rapidly increasing, however, and marriage is delayed for economic reasons.

In many Western countries, the same-sex marriage is introduced in the form of marriage based on human rights and citizenship rights such as individual rights to pursue happiness and equal rights. The first law providing for the same sex marriage was enacted in 2001 in the Netherlands. In recent years, the same sex marriage is legally recognized in many Western countries (United States, Canada, United Kingdom, Germany, France, Netherlands, Belgium, Iceland, Ireland, Luxembourg, Australia, Denmark, Sweden, Norway, Finland, Spain, Portugal, etc.).

\section{Problems with regard to the Excessive Marriage-related Expenses in South Korea}

Since recently, economic problems (low income, employment instability, etc.) and excessive marriage- and housing-related expenses have become major factors for marriage delay and for avoiding marriage all together in the South Korean society. Marriage delay and the increase of the unmarried rate are the major factors contributing to a low birthrate. The decrease in the number of married couples and the higher marriage age are closely connected to economic problems (low income, employment instability, etc.) and to excessive marriage-related expenses. In South Korea, the number of young unmarried men and women has greatly increased due to indefinite marriage delay or the decision not to get married at all owing to the continuous employment instability, the high rate of youth unemployment, the high house prices, and the excessive marriage-related expenses. According to the report of South Korea's Ministry of Health and Welfare (MOHW) on the results of its 2013 marriage and childbirth trend survey, only $67.5 \%$ of the young unmarried men survey respondents and $56.6 \%$ of the young unmarried women survey respondents expressed the belief that marriage is needed. The young unmarried women's awareness of the necessity of marriage was especially low. In addition, $40.4 \%$ of the young unmarried men and $19.4 \%$ of the young unmarried women indicated that they could not marry due to economic problems (low income, employment instability, etc.), and $87.8 \%$ of the young unmarried men indicated that employment instability is the major factor for their marriage avoidance while it was the excessive marriage expenses for $86.3 \%$ of the young unmarried women. Korea Consumer Agency (KCA) of South Korea surveyed the awareness of the pressure caused by the high marriage cost among 500 marriage-contracting parties and 500 parents (2013). The survey results are shown in Table 1.

Table 1. Survey results for marriage cost pressure awareness

\begin{tabular}{|c|c|c|c|c|c|c|c|}
\hline \multicolumn{2}{|c|}{ Classification } & \multirow{2}{*}{$\begin{array}{c}\begin{array}{c}\text { Wedding } \\
\text { cloth }\end{array} \\
3.64\end{array}$} & \multirow{2}{*}{$\begin{array}{c}\text { Wedding } \\
\text { present }\end{array}$} & \multirow{2}{*}{$\begin{array}{c}\begin{array}{c}\text { Home } \\
\text { furnishing }\end{array} \\
3.63\end{array}$} & \multirow{2}{*}{$\begin{array}{c}\begin{array}{c}\text { Wedding } \\
\text { cost }\end{array} \\
3.49\end{array}$} & \multirow{2}{*}{$\begin{array}{c}\text { Honeymoon } \\
3,52\end{array}$} & \multirow{2}{*}{$\begin{array}{c}\begin{array}{c}\text { House } \\
\text { purchase } \\
\text { cost }\end{array} \\
4.40\end{array}$} \\
\hline \multirow{3}{*}{$\begin{array}{l}\text { Marriage-contracting } \\
\text { parties }\end{array}$} & Mean & & & & & & \\
\hline & $\mathrm{N}$ & 367 & 376 & 403 & 475 & 415 & 427 \\
\hline & $\begin{array}{l}\text { Standard } \\
\text { deviation }\end{array}$ & 0.888 & 0.865 & 0.900 & 0.997 & 0.927 & 0.793 \\
\hline \multirow{3}{*}{ Parents } & Mean & 3.59 & 3.54 & 3.56 & 3.47 & 3.43 & 4.39 \\
\hline & $\mathrm{N}$ & 367 & 392 & 417 & 489 & 430 & 469 \\
\hline & $\begin{array}{l}\text { Standard } \\
\text { deviation }\end{array}$ & 0.927 & 0.951 & 0.923 & 0.943 & 0.889 & 0.779 \\
\hline
\end{tabular}

Marriage has been expanded in appearance of late for the commercial and material aspects, and the marriage cost is continuously increasing. This is the major cause of marriage avoidance and points to excessive consumption and empty formalities and vanity (Ministry of Gender Equality \& Family (MOGEF) of South Korea, 2012). The number of young unmarried men and women is greatly increasing due to the indefinite marriage delay or the decision not to get married at all owing to the escalating cost of holding a wedding. To help their children, parents give up their preparation for old age or secure a loan for their child's marriage. Economic support is given by the parents to their children to ensure the stability of the newlyweds' new life together. This, however, is done at the expense of the economic stability of the parents in their old age. To prevent this from happening, many young people in South Korea have opted to delay their marriage or even not to get married at all. As a result, the marriage rate is decreasing, and the birthrate is becoming lower.

\section{Analysis Data and Research Specimens}

In this study, the population group consisted of 1,000 persons (500 men, 500 women) in Seoul, South Korea with less than 5 years of marriage. The marriage and childbirth trend survey result report (2016) of the Ministry of Gender Equality \& Family (MOGEF) of South Korea was utilized for this study. The utilized data were samples extracted from the population group through cluster sampling. The research data were extracted through the 
framework of sampling in cluster sampling. The general characteristics of the survey sampling that was done are listed in Table 2. In this study, the dependent variables were economic support benefit and economic support provision. Economic support benefit refers to the economic assistance given by the parents of the spouses. Economic support provision, on the other hand, refers to the economic assistance given by men and women to their parents. The independent variables were the matrimonial home, marriage cost, childcare support, and housework support. The independent variables were surveyed to determine if the subjects received parental assistance for these or provided these for themselves. The control variables were the average monthly income, family size, home ownership, and number of children. The natural $\log$ value was applied to the analysis model of the average monthly income.

Table 2. General characteristics of survey sampling

\begin{tabular}{|c|c|c|c|c|c|c|}
\hline \multirow{2}{*}{ Classification } & \multirow{2}{*}{ Variable } & \multirow{2}{*}{ Response } & \multicolumn{2}{|c|}{ Mean } & \multicolumn{2}{|c|}{ Standard deviation } \\
\hline & & & $\mathrm{M}$ & $\mathrm{W}$ & M & W \\
\hline \multirow{4}{*}{$\begin{array}{l}\text { Dependent } \\
\text { variable }\end{array}$} & \multirow{2}{*}{$\begin{array}{c}\text { Economic support } \\
\text { benefit }\end{array}$} & Yes & 331 & 290 & 62 & 58 \\
\hline & & No & 169 & 210 & 38 & 42 \\
\hline & \multirow{2}{*}{$\begin{array}{l}\text { Economic support } \\
\text { provision }\end{array}$} & Yes & 269 & 281 & 54 & 56 \\
\hline & & No & 231 & 219 & 46 & 44 \\
\hline \multirow{8}{*}{$\begin{array}{l}\text { Independent } \\
\text { variable }\end{array}$} & \multirow{2}{*}{ Matrimonial home } & Parental support & 391 & 53 & 78 & 11 \\
\hline & & Self-providing & 109 & 447 & 22 & 89 \\
\hline & \multirow{2}{*}{ Marriage cost } & Parental support & 415 & 389 & 83 & 78 \\
\hline & & Self-providing & 85 & 111 & 17 & 22 \\
\hline & \multirow{2}{*}{ Childcare support } & Yes & 235 & 396 & 47 & 79 \\
\hline & & No & 265 & 104 & 53 & 21 \\
\hline & \multirow{2}{*}{ Housework } & Yes & 166 & 388 & 33 & 77 \\
\hline & & No & 334 & 112 & 67 & 23 \\
\hline \multirow{20}{*}{ Control variable } & \multirow{5}{*}{ Marriage duration } & 1 & 109 & 118 & 22 & 23 \\
\hline & & 2 & 120 & 104 & 23 & 20 \\
\hline & & 3 & 91 & 80 & 18 & 16 \\
\hline & & 4 & 102 & 92 & 20 & 19 \\
\hline & & 5 & 78 & 106 & 17 & 12 \\
\hline & \multirow{3}{*}{ Education level } & College graduation & 374 & 403 & 74 & 80 \\
\hline & & Master's graduation & 107 & 86 & 21 & 17 \\
\hline & & Doctoral graduation & 19 & 11 & 5 & 3 \\
\hline & \multirow{6}{*}{ Job } & Unemployed & 16 & 39 & 4 & 10 \\
\hline & & Temporary position & 101 & 140 & 20 & 28 \\
\hline & & Self-employed & 131 & 143 & 26 & 29 \\
\hline & & Government/public institute & 80 & 68 & 16 & 14 \\
\hline & & Large/midsize company & 118 & 87 & 23 & 17 \\
\hline & & Specialized job & 54 & 23 & 11 & 2 \\
\hline & $\begin{array}{l}\text { Average monthly } \\
\text { income }\end{array}$ & Average monthly income & $\begin{array}{l}\text { USD } \\
3,456\end{array}$ & $\begin{array}{l}\text { USD } \\
3,001\end{array}$ & - & - \\
\hline & Family size & Average number of members & 2.3 & 2.8 & - & - \\
\hline & \multirow{2}{*}{ Home ownership } & Yes & 191 & 38 & 101 & 20 \\
\hline & & No & 309 & 62 & 399 & 80 \\
\hline & \multirow{2}{*}{ Child } & Yes & 219 & 261 & 44 & 52 \\
\hline & & No & 281 & 239 & 56 & 28 \\
\hline
\end{tabular}

Note. $\mathrm{M}=\mathrm{Men}, \mathrm{W}=$ Women

\section{Research Method Design for Anal ysis}

The mean and the standard deviation were calculated for the analysis of the general characteristics of the sampling, and cross-tabulation was proposed for the analysis of the interrelations of the variables. Cross-tabulation is a method for the analysis of the correlations of the categorical variables. It is a method that utilizes frequency analysis for the mutual independence and relevance analysis of the research variables. In this research, the chi square test was utilized in the algorithm of the crosstabs for the statistical significance test. The verification statistics could be calculated through the chi square distribution. The results of the analysis showed that when the difference was significant, the variables had a correlation. Below is the detailed formula.

$$
x^{2}=\sum_{i} \sum_{j} \frac{\left(f_{i j}-E_{i j}\right)^{2}}{E_{i j}}
$$

In this study, the binary logistic regression model was utilized for the influence factor analysis of the variables. The sum of the Bernoulli trial results is the binomial distribution. Below is the detailed formula. 


$$
P(X=x)={ }_{n} C_{x} \pi^{x}(1-\pi)^{n-x}=\left(\begin{array}{l}
n \\
x
\end{array}\right) \pi^{x}(1-\pi)^{n-x}=\frac{n !}{x !(n-x) !} \pi^{x}(1-\pi)^{n-x}
$$

Below is the detailed formula for the mean of the binominal distribution.

$$
\mu=E(X)=n \pi=n p
$$

Below is the detailed formula for the variance of the binominal distribution.

$$
\sigma^{2}=E\left(S^{2}\right)=n \pi(1-\pi)=n p(1-p)=n p q
$$

\section{Anal ysis Resul ts and Interpretation}

Cross-tabulation and correlation analysis were conducted for economic, housework, and childcare support, and the results are shown in Table 3. For economic support, $83 \%$ of the male survey respondents and $79 \%$ of the female survey respondents were receiving childcare support from their parents while $66 \%$ of the men and $71 \%$ of the women were receiving housework support. Twelve percent of the men and $5 \%$ of the women were not receiving childcare support from their parents, and $44 \%$ of the men and $11 \%$ of the women were not receiving housework support from them. These results may indicate that economic, housework, and childcare support are provided all together. The correlation coefficients of economic and childcare support are 0.599 for the men and 0.590 for the women while those of economic and housework support are 0.621 for the men and 0.611 for the women. When men and women are receiving economic support from their parents, childcare and housework support are almost always provided as well. In other words, married men and women are being supported in various ways by their parents.

Table 3. Analysis of economic, housework, and childcare support

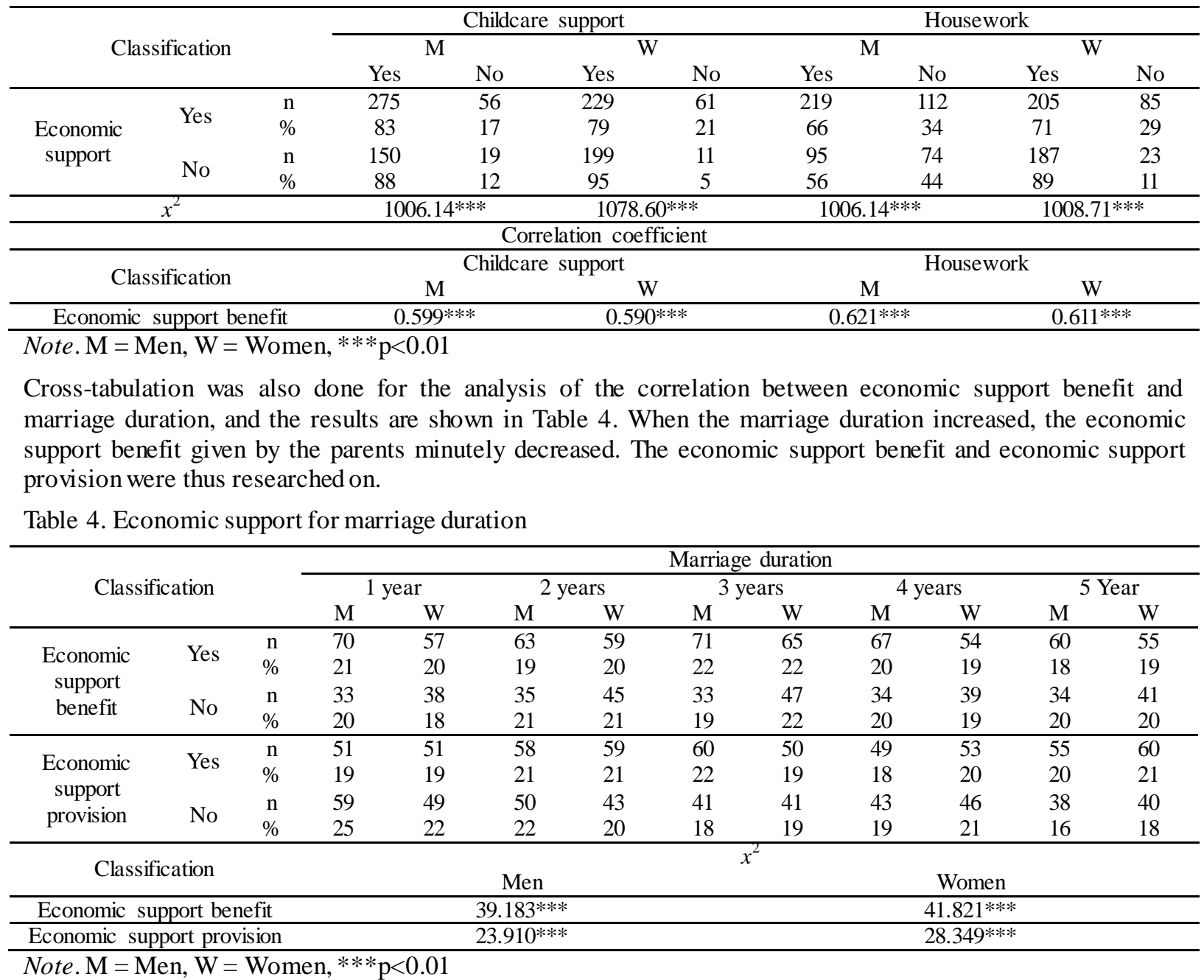


The economic support for the marriage-related expenses and the matrimonial home purchase cost is shown in Table 5.

Table 5. Economic support for marriage cost and matrimonial home

\begin{tabular}{|c|c|c|c|c|c|c|}
\hline \multirow{2}{*}{\multicolumn{3}{|c|}{ Classification }} & \multicolumn{4}{|c|}{ Marriage cost } \\
\hline & & & \multicolumn{2}{|c|}{$\mathrm{M}$} & \multicolumn{2}{|c|}{$\mathrm{W}$} \\
\hline & & & Parental support & Self-providing & Parental support & Self-providing \\
\hline \multirow{5}{*}{$\begin{array}{c}\text { Economic } \\
\text { support } \\
\text { benefit }\end{array}$} & \multirow{2}{*}{ Yes } & $\mathrm{n}$ & 281 & 50 & 235 & 55 \\
\hline & & $\%$ & 85 & 15 & 81 & 19 \\
\hline & \multirow{2}{*}{ No } & $\mathrm{n}$ & 130 & 39 & 176 & 34 \\
\hline & & $\%$ & 48 & 52 & 84 & 16 \\
\hline & \multicolumn{2}{|c|}{$x^{2}$} & \multicolumn{2}{|c|}{$4.131^{*}$} & \multicolumn{2}{|c|}{$5.058^{*}$} \\
\hline \multirow{5}{*}{$\begin{array}{l}\text { Economic } \\
\text { support } \\
\text { provision }\end{array}$} & \multirow{2}{*}{ Yes } & $\mathrm{n}$ & 207 & 62 & 249 & 32 \\
\hline & & $\%$ & 77 & 23 & 89 & 11 \\
\hline & \multirow{2}{*}{ No } & $\mathrm{n}$ & 185 & 46 & 190 & 29 \\
\hline & & $\%$ & 80 & 20 & 86 & 14 \\
\hline & \multicolumn{2}{|c|}{$x^{2}$} & \multicolumn{2}{|c|}{$18.790 * * *$} & \multicolumn{2}{|c|}{$17.103 * * *$} \\
\hline \multirow{3}{*}{\multicolumn{3}{|c|}{ Classification }} & \multicolumn{4}{|c|}{ Matrimonial home } \\
\hline & & & \multicolumn{2}{|c|}{$\bar{M}$} & \multicolumn{2}{|c|}{$\mathrm{W}$} \\
\hline & & & Parental support & Self-providing & Parental support & Self-providing \\
\hline \multirow{5}{*}{$\begin{array}{c}\text { Economic } \\
\text { support } \\
\text { benefit }\end{array}$} & \multirow{2}{*}{ Yes } & $\mathrm{n}$ & 263 & 68 & 259 & 31 \\
\hline & & $\%$ & 80 & 20 & 89 & 11 \\
\hline & \multirow{2}{*}{ No } & $\mathrm{n}$ & 146 & 23 & 150 & 19 \\
\hline & & $\%$ & 54 & 46 & 71 & 29 \\
\hline & \multicolumn{2}{|c|}{$x^{2}$} & \multicolumn{2}{|c|}{0.106} & \multicolumn{2}{|c|}{0.091} \\
\hline \multirow{5}{*}{$\begin{array}{l}\text { Economic } \\
\text { support } \\
\text { provision }\end{array}$} & \multirow{2}{*}{ Yes } & $\mathrm{n}$ & 249 & 20 & 261 & 20 \\
\hline & & $\%$ & 93 & 7 & 91 & 9 \\
\hline & \multirow{2}{*}{ No } & $\mathrm{n}$ & 188 & 43 & 207 & 12 \\
\hline & & $\%$ & 81 & 19 & 95 & 5 \\
\hline & \multicolumn{2}{|c|}{$x^{2}$} & \multicolumn{2}{|c|}{$14.010 * * *$} & \multicolumn{2}{|c|}{$16.714 * * *$} \\
\hline
\end{tabular}

Note. $\mathrm{M}=\mathrm{Men}, \mathrm{W}=$ Women, $* \mathrm{p}<0.1, * * \mathrm{p}<0.05, * * * \mathrm{p}<0.01$

Eighty five percent of the male subjects and $81 \%$ of the female subjects received economic support for their marriage-related expenses from their parents while $85 \%$ of the former and $81 \%$ of the latter provided for themselves. The chi-squared value was significant, with a $90 \%$ confidence level. The matrimonial home purchase cost economic support from the parents was not statistically significant, but the economic support for the marriage-related expenses was. The percentage of men who received marriage-related expenses economic support from their parents was $77 \%$, and the percentage of women who received the same from their parents was $89 \%$. The percentage of men who received matrimonial home economic support from their parents was $93 \%$, and the percentage of women who received the same from their parents was $91 \%$. These results are more statistically significant than the percentages of the men and women who provided for themselves.

Logistic regression was done for the influence factor analysis, with economic support benefit and economic support provision as the dependent variables. These were statistically significant. The results of the influence factor analysis are presented in Table 6. 
Table 6. Influence factor analysis

\begin{tabular}{|c|c|c|c|c|c|}
\hline & \multirow{3}{*}{ Classification } & \multicolumn{4}{|c|}{ Economic support benefit } \\
\hline & & \multicolumn{2}{|c|}{$\mathrm{M}(\mathrm{n}=500)$} & \multicolumn{2}{|c|}{$\mathrm{W}(\mathrm{n}=500)$} \\
\hline & & $\mathrm{B}$ & Odds ratio & $\mathrm{B}$ & Odds ratio \\
\hline \multirow{2}{*}{$\begin{array}{c}\text { Dependent } \\
\text { variable }\end{array}$} & Economic support benefit (No) & -0.503 & 0.671 & 0.108 & 0.359 \\
\hline & Economic support provision (No) & - & - & - & - \\
\hline \multirow{4}{*}{$\begin{array}{l}\text { Independent } \\
\text { variable }\end{array}$} & $\begin{array}{c}\text { Matrimonial home } \\
\text { (Parental support) }\end{array}$ & 0.678 & 1.059 & 0.450 & 1.141 \\
\hline & Marriage cost (Parental support) & -0.033 & 0.837 & $-0.021 *$ & 0.931 \\
\hline & Childcare support (No) & $1.063 * * *$ & 6.517 & $1.716^{* * *}$ & 3.145 \\
\hline & Housework (No) & $1.821 * * *$ & 5.170 & $1.347 * * *$ & 4.583 \\
\hline \multirow{7}{*}{$\begin{array}{l}\text { Control } \\
\text { variable }\end{array}$} & Marriage duration & 0.008 & 1.106 & -0.313 & 1.110 \\
\hline & Education level & 0.117 & 1.017 & 0.230 & 1.008 \\
\hline & Job & $-0.061 *$ & 0.515 & $-0.070^{*}$ & 0.900 \\
\hline & Average monthly income & $-0.471 * * *$ & 0.615 & $-0.381 * * *$ & 0.564 \\
\hline & Family size & $-0.171 *$ & 0.917 & $-0.239 *$ & 1.001 \\
\hline & Home ownership (No) & -0.061 & 0.871 & -0.058 & 0.770 \\
\hline & Child (No) & -0.331 & 1.213 & -0.238 & 1.008 \\
\hline & Constant term & 1.116 & 3.870 & 1.406 & 5.101 \\
\hline & Model $x^{2}$ & \multicolumn{2}{|c|}{$1210.391 * * *$} & \multicolumn{2}{|c|}{$1099.410 * * *$} \\
\hline & -2 log likelihood & \multicolumn{2}{|c|}{2010.45} & \multicolumn{2}{|c|}{3014.17} \\
\hline & Nagelkerke $R^{2}$ & \multicolumn{2}{|c|}{0.671} & \multicolumn{2}{|c|}{0.717} \\
\hline & \multirow{3}{*}{ Classification } & \multicolumn{4}{|c|}{ Economic support provision } \\
\hline & & \multicolumn{2}{|c|}{$\mathrm{M}(\mathrm{n}=500)$} & \multicolumn{2}{|c|}{$\mathrm{W}(\mathrm{n}=500)$} \\
\hline & & $\mathrm{B}$ & Odds ratio & $\mathrm{B}$ & Odds ratio \\
\hline \multirow{2}{*}{$\begin{array}{l}\text { Dependent } \\
\text { variable }\end{array}$} & Economic support benefit (No) & - & - & - & - \\
\hline & Economic support provision (No) & $-0.506 * * *$ & 0.670 & 0.091 & 0.353 \\
\hline \multirow{4}{*}{$\begin{array}{c}\text { Independent } \\
\text { variable }\end{array}$} & $\begin{array}{c}\text { Matrimonial home } \\
\text { (Parental support) }\end{array}$ & $-0.308 * * *$ & 0.854 & $-0.235^{* *}$ & 0.768 \\
\hline & Marriage cost (Parental support) & -0.129 & 0.719 & 0.001 & 0.871 \\
\hline & Childcare support (No) & -0.180 & 0.551 & -0.019 & 0.495 \\
\hline & Housework (No) & $0.451 * *$ & 1.708 & $0.391 * * *$ & 1.047 \\
\hline \multirow{7}{*}{$\begin{array}{l}\text { Control } \\
\text { variable }\end{array}$} & Marriage duration & -0.041 & 0.881 & -0.091 & 0.003 \\
\hline & Education level & 0.147 & 1.001 & 0.106 & 1.081 \\
\hline & Job & $-0.017 * *$ & 0.340 & -0.067 & 1.740 \\
\hline & Average monthly income & $0.747 * * *$ & 1.901 & $0.593 * * *$ & 1.070 \\
\hline & Family size & 0.017 & 1.030 & 0.131 & 0.933 \\
\hline & Home ownership (No) & -0.001 & 0.885 & -0.034 & 0.901 \\
\hline & Child (No) & 0.014 & 0.718 & 0.003 & 0.839 \\
\hline & Constant term & 1.116 & -0.671 & 0.005 & -0.443 \\
\hline & Model $x^{2}$ & \multicolumn{2}{|c|}{$1210.391^{* * *}$} & \multicolumn{2}{|c|}{$141.03^{* * *}$} \\
\hline & -2 log likelihood & \multicolumn{2}{|c|}{2010.45} & \multicolumn{2}{|c|}{2987.693} \\
\hline & Nagelkerke $R^{2}$ & \multicolumn{2}{|c|}{0.671} & \multicolumn{2}{|c|}{0.070} \\
\hline
\end{tabular}

Two models were interpreted and compared for statistical significance. The two models consisted of the control variables for economic support benefit and those for economic support provision. The number of subjects who received matrimonial home purchase economic support was statistically significant. When matrimonial home support was received from the parents, the economic support provision by the parents increased. This result indicates long-term reciprocity between the parents and their children. Also, the economic support for the marriage-related expenses was found to have had long-term reciprocity and to have been statistically significant. In the economic support benefit model, the childcare, housework, and economic support benefits were statistically significant. In the economic support provision model, housework support was statistically significant. When childcare or housework support was provided by the parents, the probability of the children receiving economic support increased. This means that parents provide their children with various kinds of support. When economic support is provided by the parents, the probability of the parents receiving economic support from their children is low. This means that the reciprocal relationship is not short-term. In the economic support provision model, housework and economic support provision showed a positive relationship. The provision of housework support by the parents increased the probability of their economic support provision to their children. They showed a reciprocal relationship in the short term. The statistically significant variables are as follows. The job, average monthly income, family size, and number of children of the subjects showed a statistically significant relationship with economic support benefit. In the economic support benefit model, the economic 
support benefit probability decreased for the male and female subjects who had an occupation, whose average monthly income was high, and who had a large family. The economic support benefit probability increased, however, with childcare support. When the average monthly income was high, the economic support provision probability was also high.

\section{Policy Discussion for Addressing the Problem of Excessive Marriage-related Expenses}

In South Korea, the major causes of excessive marriage-related expenses are the psychological factor on the part of men and women, the social structural factor, the wrong set of values of the people, the parental psychological factor, the bombastic propaganda of mass media, and the specialized marriage market. The regulation policy of the government is essential for preventing excessive consumption. For instance, in South Korea, the rental house supply has focused on the lower-income group. The ne wlywed support policy should be expanded to include the provision of economic support to those beyond the lower-income group. Also, the relevant go vernment policy should focus on the provision of rental house supply and house purchase cost economic support for newlyweds. Active support is also needed for the government-led supply of cheap housing. In addition, in South Korea, the societal tendencies are the core factor contributing to the excessive marriage-related expenses. That is, the people want to put their economic status and personal fame on exhibit through conspicuous consumption. The overall efforts of the society are thus needed to be able to address the problem of excessive marriage-related expenses. On the part of the marriage-contracting parties, their efforts are also very important in addressing the aforementioned problem of excessive marriage-related expenses in South Korea. For one, the said expenses should be divided equally between them based on egocentrism and the principle of equality. The contracting parties should also prepare for their future marriage and family expenditures by limiting their daily expenditures. Developing a desirable set of values is very important for marriage. Furthermore, a premarital education program is needed for the marriage-contracting parties and their parents. Small weddings and desirable consumption should be aggressively promoted for the prevention of excessive marriage-related expenses. Couples should also have already worked for more than 10 years before getting married so that they could afford the purchase cost of a house in Seoul.

As mentioned earlier, in South Korea, many young unmarried men and women are avoiding marriage or have decided not to get married at all due to the excessive marriage-related expenses and the very high house purchase cost. The house purchase cost is also the major factor contributing to the indefinite marriage delay. The parents shoulder the house purchase cost for their child, but this threatens the economic stability of the parents in old age. Therefore, the economic dependence of children should be decreased for the sake of the parents. The government should develop and promote an exemplary marriage model. A wedding product and service information comparison system should also be constructed, and public facilities should be utilized as wedding halls.

\section{Conclusions}

The excessive marriage-related expenses in South Korea have given rise to various other social problems, such as marriage delay, marriage abandonment, and a low birthrate. Job, marriage, and childbirth abandonment have become social buzzwords and serious social problems in South Korea of late. The marriage rate is decreasing and the birthrate is continuously becoming lower due to the indefinite marriage delay or the decision not to get married at all. South Korea has already entered the realm of an aging society due to its low birthrate and increasing aging population. This causes productivity decline and low economic growth through a decrease in the productive population of the country.

The young unmarried men or women in the country generally cannot adequately prepare themselves to shoulder the purchase cost of their house after getting married. Thus, their parents purchase their house for them. In South Korea, the parental support, however, does not end here. If the child requests for economic support after marriage, the parents oblige through economic resource transfer. This has become a serious social problem in South Korea. The number of young unmarried men and women is greatly increasing due to the indefinite marriage delay or the decision not to get married at all owing to the prohibitive cost of getting married. To help their children, parents give up preparing for their old age or secure a loan for their children. The economic support from the couple's parents contributes to the life stability of the newlyweds but threatens the economic stability of the couple's parents in old age. The lack of work and leisure for the country's aged population has also emerged as a social problem.

In this research, 1,000 persons (500 men, 500 women) in Seoul with less than 5 years of marriage were surveyed for excessive marriage-related expenses analysis. The marriage and childbirth trend survey results report (2016) of the Ministry of Gender Equality \& Family (MOGEF) of South Korea was utilized for this purpose. The utilized data were extracted as a sample from the population group, through cluster sampling. The research data 
were extracted through the framework of sampling in cluster sampling. Logistic regression was conducted for the influence factor analysis. Economic support benefit and economic support provision were the dependent variables, and they were found to be statistically significant. From this it was determined that the parental economic support for the marriage-related expenses has statistically significant long-term reciprocity. In the economic support benefit model, the childcare, housework, and economic support provision were also statistically significant. In the economic support provision model, the housework support provision was statistically significant. That is, when childcare or housework support was provided, the probability of receiving economic support benefit increased. This means that the parents provide their children with various kinds of support.

This paper discusses and presents the policy direction for addressing the problem of excessive marriage-related expenses. It is expected that the proposed policy direction for addressing the problem of excessive marriage-related expenses will contribute to the prevention thereof, and of marriage delay. It is also believed that the policy direction proposed in this paper will have global implications and will be able to help address the problem of excessive marriage-related expenses through research result sharing.

\section{References}

Allendorf, K., \& Ghimire, D. J. (2013). Determinants of marital quality in an arranged marriage society. Social Science Research, 42(1), 59-70. https://doi.org/10.1016/j.ssresearch.2012.09.002

Amato, P. R. (2007). Transformative processes in marriage: some thoughts from a sociologist. Journal of Marriage and the Family, 69(2), 305-309. https://doi.org/10.1111/j.1741-3737.2007.00365.x

Brake, E. (2007). Marriage, morality, and institutional value. Ethical Theory and Moral Practice, 10(3), 243-254. https://doi.org/10.1007/s10677-007-9066-6

Carrington, C. (2002) Marriage. Qualitative Sociology, 25(1), 165-168. https://doi.org/10.1023/A:1014380913536

Fincham, F. D., Stanley, S. M., \& Beach, S. R. (2007). Transformative processes in marriage: An analysis of emerging trends. 69(2), 275-292. https://doi.org/10.1111/j.1741-3737.2007.00362.x

Gottman, J., Swanson, C., \& Swanson, K. (2002). A general systems theory of marriage: nonlinear difference equation modeling of marital interaction. Personality and Social Psychology Review, 6(4), 326-340. https://doi.org/10.1207/S15327957PSPR0604_07

Groot, W. \& Van Den Brink, H. M. (2003). Match Specific Gains to Marriage: A Random Effects Ordered Response Model. 37(3), 317-325.

Jackson, G. L., Krull, J. L., Bradbury, T. N., \& Karney, B. R. (2017). Household income and trajectories of marital satisfaction in early marriage. Journal of Marriage and the Family, 79(3), 690-704. https://doi.org/10.1111/jomf.12394

Korea National Statistical Office (KOSTAT) (2016). The statistics report, Korea National Statistical Office (KOSTAT) of South Korea.

Lefgren, L., \& McIntyre, F. (2006). The relationship between women's education and marriage outcomes. Journal of labor economics, 24(4), 787-830. https://doi.org/10.1086/506486

Legros, P., \& Newman, A. (2010). Co-ranking mates: Assortative matching in marriage markets. Economics letters, 106(3), 177-179. https://doi.org/10.1016/j.econlet.2009.11.013

Lin, W. F., Li, T. S., \& Chen, L. H. (2017). Sacrifice in a Supportive Marriage: Social Support as a Moderator Buffers the Negative Effects of Sacrifice in Marriage. Journal of Happiness Studies, 18(2), 575-589. https://doi.org/10.1007/s10902-016-9738-9

Madison, J. K. \& Madison, L. S. (2013). A Review of Research-Based Interventions on Marriage Preparation. Journal of Rational Emotive and Cognitive Behavior Therapy, 31(2), 67-74. https://doi.org/10.1007/s 10942-013-0160-5

Mair, J. (2006). A Modern Marriage? Edinburgh Law Review, 10(3), 333-351. https://doi.org/10.3366/elr.2006.10.3.333

McKenzie, L., \& Dales, L. (2017). Choosing love? Tensions and transformations of modern marriage in married at first sight. Continuum - Murdoch then mt lawley, 31(6), 857-867. https://doi.org/10.1080/10304312.2017.1334873 
Meltzer, A. L., Novak, S. A., McNulty, J. K., Butler, E. A., \& Karney, B. R. (2013). Marital satisfaction predicts weight gain in early marriage. Health psychology, 32(7), 824-827. https://doi.org/10.1037/a0031593

Mincy, R., Hill, J., \& Sinkewicz, M. (2009). Marriage: Cause or mere indicator of future earnings growth? 28(3), Journal of Policy Analysis and Management, 28(3), 417-439. https://doi.org/10.1002/pam.20439

Ministry of Gender Equality \& Family (MOGEF). (2016). The marriage and childbirth trend survey result report, Ministry of Gender Equality \& Family (MOGEF) of South Korea.

Ministry of Health and Welfare (MOHW). (2013). The marriage and childbirth trend survey, Ministry of Health and Welfare (MOHW) of South Korea.

Quinn, M., \& Lockhart, D. (2007). Happy marriage. BRW Media, 29(39), 72.

Sherman, A. J., \& Badillo, A. (2007). Marriage rehearsal: How to prepare for the deal. Journal of corporate accounting and finance, 18(2), 3-11. https://doi.org/10.1002/jcaf.20270

Singh, K. (2012). Towards achieving equal rights in marriage. Economic and Political Weekly, 47(24), 17-19.

Wong, L. Y. (2003). Structural estimation of marriage models. 21(3), 699-728. https://doi.org/10.1086/374964

\section{Copyrights}

Copyright for this article is retained by the author(s), with first publication rights granted to the journal.

This is an open-access article distributed under the terms and conditions of the Creative Commons Attribution license (http://creativecommons.org/licenses/by/4.0/). 